\title{
Suprasellar ectopic pituitary adenoma presenting as cranial diabetes insipidus
}

\author{
K.H. Luk, Karen S.L. Lam, Annie W.C. Kung, C.F. Fung ${ }^{1}$ and S.Y. Leung ${ }^{2}$
}

Departments of Medicine, ${ }^{1}$ Surgery and ${ }^{2}$ Pathology, University of Hong Kong, Queen Mary Hospital, Hong Kong

\begin{abstract}
Summary: We describe the occurrence of a supracellar ectopic pituitary adenoma in a 34 year old woman who presented with cranial diabetes insipidus and subsequently developed galactorrhoea-amenorrhoea. The tumour was demonstrated by both contrast computed tomography scan and magnetic resonance imaging with gadolinium enhancement and was confirmed at operation. Histological examination showed that the suprasellar lesion consisted of a pituitary adenoma while the pituitary biopsy revealed an unrelated pituitary microadenoma embedded in normal pituitary tissues. A review is made of the reported cases of ectopic pituitary adenomas.
\end{abstract}

\section{Introduction}

Endheim described in 1909 the first case of ectopic pituitary adenoma. ${ }^{1}$ Including the present case, a total of 25 cases have since been reported. ${ }^{1-20}$ The majority of these tumours were found in extracranial sites. Even among those occurring intracranially, none presented with diabetes insipidus. We report here a patient with a suprasellar pituitary adenoma who presented with cranial diabetes insipidus.

\section{Case report}

A 34 year old woman, previously enjoying good health, noticed polyuria and polydipsia in February 1989. Three months later, she developed secondary amenorrhoea associated with galactorrhoea, but had no headache and no visual disturbance. At a district general hospital, apart from bilateral galactorrhoea, physical examination showed no abnormal findings. Fundi and visual fields were normal. Her overnight serum and urine osmolalities were 302 and $120 \mathrm{mosmol} / \mathrm{kg}$, respectively, in keeping with the diagnosis of diabetes insipidus. The corresponding serum sodium was $150 \mathrm{mmol} / \mathrm{l}$. She was also found to have a raised serum prolactin of $2254 \mathrm{mU} / 1$ (normal less than $500 \mathrm{mU} / \mathrm{l})$. Other basal hormone levels including serum thyroxine (T4), FTI (free thyroxine index), thyroid stimulating hormone (TSH), cortisol, ACTH, growth hormone, follicle stimulating hor-

Correspondence: K.S.L. Lam, M.D., F.R.C.P. Accepted: 28 October 1991 mone (FSH) and luteinizing hormone (LH) levels were within normal limits. Computed tomographic (CT) scan of the hypothalamic-pituitary region (coronal sections only) showed no abnormal findings. Her diabetes insipidus and galactorrhoea responded to treatment with intranasal DDAVP and bromocriptine, respectively. However, she remained amenorrhoeic despite the correction of hyperprolactinaemia and was therefore referred to the Endocrine Unit, Queen Mary Hospital, for further management.

Endocrine assessment in November 1990 showed that she had markedly impaired LH and FSH responses to LH releasing hormone (LHRH) and no growth hormone response to insulininduced hypoglycaemia. Plasma cortisol response to hypoglycaemia was also impaired (peak level $542 \mathrm{nmol} / 1$; normal $\geqslant 720 \mathrm{nmol} / \mathrm{l}$ ). She also had mild hypothyroidism (FTI being 69 only; normal $\geqslant 76$ ). Serum TSH levels were normal basally and following thyrotrophin releasing hormone (TRH) stimulation. In view of the presence of panhypopituitarism, CT scan of the hypothalamicpituitary region was repeated in November 1990. A soft tissue swelling involving the posterior hypothalamus and associated with marked contrast enhancement was seen. The pituitary gland was normal. A review of the CT scan performed in 1989 showed inadequate imaging of the posterior hypothalamus. For better delineation of the suprasellar lesion, magnetic resonance imaging (MRI) with gadolinium injection was performed (Figure 1). A well-circumscribed oval-shaped mass was seen in the hypothalamus at midline, involving the floor of the anterior part of the third ventricle. It measured $12.7 \mathrm{~mm}$ antero-posteriorly, $5.1 \mathrm{~mm}$ ver- 
tically and $10.3 \mathrm{~mm}$ tranversely, and was diffusely enhanced by gadolinium. The tumour infiltrated the pituitary stalk and extended into a small portion of the posterior portion of the pituitary gland. The bulk of the pituitary showed normal enhancement. The patient underwent a pterional craniotomy with partial removal of the suprasellar tumour. No significant change in pituitary function was detected after the operation. She was treated with a course of external irradiation and was maintained on hormonal replacement.

Histopathological studies showed that the suprasellar tumour had the structure of a pituitary adenoma with the neoplastic cells arranged in cords and nests separated by sinusoids (Figure 2). Most of the cords were monotonous in appearance and

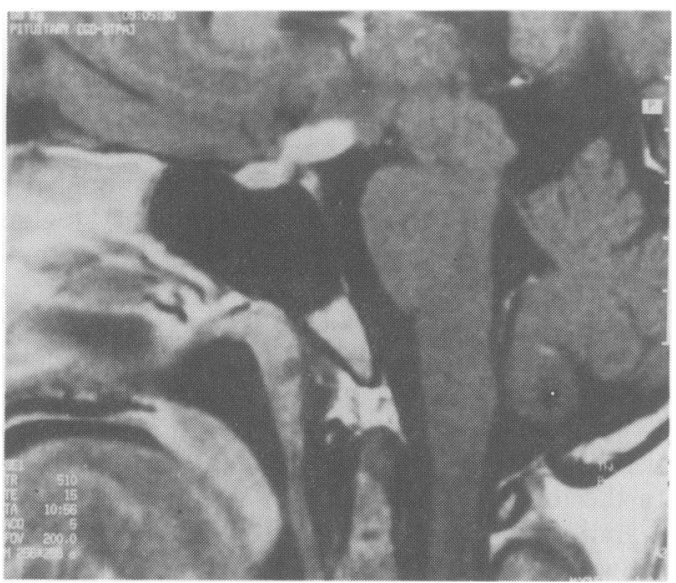

Figure 1 MRI with gadolinium injection showing the oval-shaped suprasellar mass which was diffusely enhanced by gadolinium.

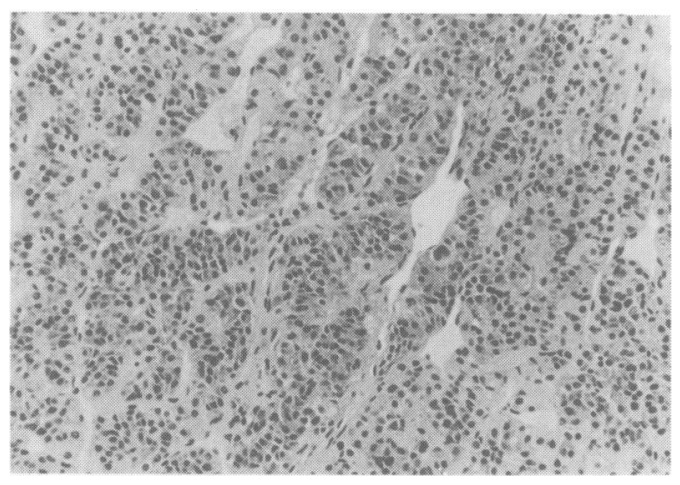

Figure 2 Section shows a pituitary adenoma with endocrine cells arranged in trabeculae, closely associated with vascular sinusoids $(\mathrm{H} \& \mathrm{E} \times 400)$. possessed amphophilic cytoplasm. Immunostaining was negative for ACTH, growth hormone, prolactin, TSH and the gonadotrophins. Multiple small biopsies of the pituitary were also taken and showed the structure of normal pituitary tissues, except for a circumscribed microadenoma of about $1 \mathrm{~mm}$ in diameter which consisted of ACTHpositive cells.

\section{Discussion}

The suprasellar ectopic pituitary adenoma in this case was well demonstrated by contrast CT scan and MRI with gadolinium injection, and was subsequently confirmed in operation and by histopathological findings. Although the pathology of the pituitary gland showed a well-circumscribed microadenoma of about $1 \mathrm{~mm}$ in diameter embedded in normal pituitary tissue, it was most likely an incidental finding unrelated to the suprasellar tumour since they were essentially. of different histology.

Including the present case, 25 cases of ectopic pituitary adenoma have been reported so far. ${ }^{1-20}$ Patients observed tended to be young, with a mean age of 40 and a male to female ratio of about $2: 1$. Only eight cases were intracranial ${ }^{3,5,6,15,18-20}$ with $\varnothing \overrightarrow{0}$ the suprasellar region being the commonest location. The rest of the cases were extracranial with the sphenoid sinus being most frequently involved.

Two theories have been derived to account for the pathogenesis of ectopic pituitary adenomas. The first is that adenomatous change occurs in ectopic pituitary tissues deposited along the route of fetal pituitary development. The anterior pituitary gland develops from Rathke's pouch while the posterior pituitary gland originates from the infundibilum. When Rathke's pouch migrates upwards, it leaves behind ectopic pituitary tissues in its path: In fact, ectopic pharyngeal pituitary ${ }^{21}$ and suprasellar ectopic pituitary ${ }^{22}$ have already been shown to be common structures in brain autopsies and may play a role in the hormonal control of the body. ${ }^{23,24}$ Adenomatous change of these ectopic pituitary tissues would lead to the formation of ectopic pituitary adenomas.

The second theory is that of tumour dissemination. Most pituitary adenomas are benign but a small minority may spread by infiltration, blood metastasis, meningeal or cerebrospinal fluid spreading. Ectopic pituitary adenoma suspected to be caused by tumour metastasis has been previously reported. ${ }^{8}$

Previously reported cases of ectopic pituitary adenomas either presented with mechanical symptoms like headache, epilepsy, ocular paresis, visual field defect, or with hormonal symptoms like acromegaly, Cushing's syndrome, amenorrhoea, 
or both. ${ }^{1-20}$ Even among those occurring intracranially none presented with diabetes insipidus. Our patient appears to be the first reported case of ectopic pituitary adenoma to present with cranial diabetes insipidus.

\section{References}

1. Endheim, J. Uber einen Hypophysen tumor van ungewohnlichem Sitz. Beitr Pathol Anat 1909, 46: 223-249.

2. Kepes, J.J. \& Fritzlen, T.J. Large invasive chromophobe adenoma with a well preserved pituitary gland. Neurology 1964, 14: 537-541.

3. Ortiz-Suarez, H. \& Erickson, D.L. Pituitary adenoma of adolescents. $J$ Neurosurg 1975, 43: 437-439.

4. Chessin, H., Urdanta, N., Smith, H. \& Gilder, J.V. Chromophobe adenoma manifesting as nasopharyngeal mass. Arch Orolaryngol 1976, 102: 631-633.

5. Rothman, L.M., Sher, J., Quencer, R.M. \& Tenner, M.S Intracranial ectopic adenoma. Case report. $J$ Neurosurg 1976 , 44: 96-99.

6. Bonner, R.A., Mukai, K. \& Oppenheimer, J.H. Two unusual variants of Nelson's Syndrome. J Clin Endocrinol Metab 1979, 49: 23-29.

7. Borit, A. \& Blanshard, T.P. Sphenoidal pituitary adenoma. Human Pathol 1979, 10: 93-96.

8. Rasmussen, P. \& Lindholm, J. Ectopic pituitary adenomas. Clin Endocrinol 1979, 11: 69-74.

9. Kammer, H. \& George, R. Cushing's disease in a patient with ectopic pituitary adenoma. JAMA 1981, 246: 2722-2725.

10. Warner, B.A., Santen, R.J. \& Page, R.B. Growth hormone and prolactin secretion by a tumour of the pharyngeal pituitary. Ann Intern Med 1982, 96: 65-66.

11. Matsushita, H., Matsuya, S., Endo, Y. et al. A prolactin producing tumour originated in the sphenoid sinus. Acta Pathol Japan 1984, 34: 103-109.

12. Burch, W.M., Kramer, R.S., Kena, P.D. \& Hammond, C.B. Cushing's disease caused by an ectopic pituitary adenoma within the sphenoid sinus. $N$ Engl J Med 1985, 312: 587-588.

13. Shenker, Y., Lloyd, R.V., Weatherbee, L., Port, F.K., Grekin, R.J. \& Barkan, A.L. Ectopic prolactinoma in patient with hyperparathyroidism and abnormal sellar radiography. $J$ Clin Endocrinol Metab 1986, 62: 1065-1069.

\section{Acknowledgement}

We thank the nursing staff of the E2 Metabolic ward for performing the endocrine tests and Miss Venus Yuen for secretarial assistance.

14. Lloyd, R.V., Chandler, W.F., Kovacs, K.\& Ryan, N. Ectopic pituitary adenomas with normal anterior pituitary glands. Am J Surg Pathol 1986, 10: 546-552.

15. Neilson, K.\& de Chadarevian, J.P. Ectopic anterior pituitary corticotrophic tumour in a six-year-old boy. Histological, ultrastructure and immunochemical study. Virchows Arch $A$ 1987, 411: 267-273.

16. Schteingart, D.E., Chandler, W.F., Lloyd, R.V. \& IbarraPerez, G. Cushing's syndrome caused by an ectopic pituitary adenoma. Neurosurg 1987, 21: 223-227.

17. Heitzmann, A., Jan, M., Lecomte, P., Ruchoux, M.M., Lhuintre, Y. \& Tillet, Y. Ectopic pituitary within the sphenoid sinus. Neurosurg 1989, 24: 279-282.

18. Matsumura, A., Meguro, K., Doi, M., Tsurushima, H. \& Tomono, Y. Suprasellar ectopic pituitary adenoma. Case report and review of the literature. Neurosurg 1990, 26: $681-684$.

19. Kleinschmidt-De Masters, B.K., Winston, K.R., Rubinstein D. \& Samuels, M.H. Ectopic pituitary adenoma of the third ventricle. $J$ Neurosurg 1990, 72: 139-142.

20. Hamada, J., Seto, H., Miura, M., Kuratsu, J. \& Ushio, Y. Suprasellar pituitary adenoma arising from the pars tuberalis. Case report. Neurosurg 1990, 27: 647-649.

21. Daniel, R.C., Libertad, A.P. \& Arturo, O.S. Identification of seven hormone-producing cell types in the human pharyngeal hypophysis. J Clin Endocrinol Metabol 1985, 60: 212-215.

22. Akira, H. Suprasellar peri-infundibular ectopic adenohypophysis in fetal and adult brains. $J$ Neurosurg 1985 , 63: $113-119$

23. Lindholm, J., Korsgaard, O. \& Rasmussen, P. Ectopic pituitary function. Acta Med Scand 1975, 198: 299-302

24. McGrath, $P$. The trans-sphenoidal vascular route in relation to the human pharyngeal hypophysis. J Anat 1972, 113: 383. 